\title{
The Bicuspid Aortic Valve
}

\author{
Mehmet Demir \\ Additional information is available at the end of the chapter \\ http://dx.doi.org/10.5772/52567
}

\section{Introduction}

Bicuspid aortic valve (BAV) represents the most common cardiac congenital malformation in the adult age, with strong male predominance. It may occur in isolation, or in association with other congenital heart diseases. The BAV is seen in $1 \%$ to $2 \%$ of the population and may be complicated by aortic stenosis or aortic insufficiency and infective endocarditis. It may be associated with abnormalities of the aortic wall such as coarctation of the aorta, aortic dissection, and aortic aneurysm. Most patients with a BAV develop some complications during life [1,2].

Congenital coronary anomalies, coronary atherosclerosis, and calcification have been described in association with BAV[3].

BAV has been identified at a prevalence of 4.6 cas-es per 1000 live births. The prevalence of BAV according to sex has been found to be 7.1 cases per 1000 among male neonates, and 1.9 per 1000 among female neonates.

The congenitally BAV may function normally throughout life, may develop progressive calcification and stenosis or may develop regurgitation with or without infection. Aortic root dilatation is common in BAV, even when the valve is haemodynamically normal, and consequently aortic dissection usually occurs in previously asymptomatic patients [4,5].

Aortic stenosis and regurgitation, infective endocarditis and aortic dissection are the most common complications. Left coronary artery dominance is more common in patients with a BAV $(29-56.8 \%)$ and in $90 \%$ of cases, the left main coronary artery is less than $5 \mathrm{~mm}$ in length [6-8]. The ignorance of these associations may cause an inadequate myocardial preservation and an increased risk of myocardial infarction[9,10]. 
Accordingly, associated congenital cardiovascular anomalies have been reported in as many as $25 \%$ of patients. Patent ductus arteriosus and ventricular septal defect are the most frequent heart defects associated with BAVdisease [11].

\subsection{Embryology and pathogenesis}

The definitive fetal cardiac structure is evident from the second week of gestation, whereas separation of the heart into four chambers is completed during the sixth and seventh weeks of gestation resulting in separated systemic and pulmonary circulation[12]. The process of aortic valve morphogenesis begins from the cardiac cushions located in the ventricular outflow tract of the primary heart tube. In the outflow tract, the truncal cushion swellings contribute to form three leaflet valves of the aorta and pulmonary artery.The initial endocardial cushions, which will contribute to all four cardiac valves, are formed by the thickening of the extracellular matrix in the region of the atrioventricular and outflow tract.This process is initiated by the secretion of extracellular matrix proteins such as fibronectin and transferrin across the cardiac jelly to the adjacent endocardium. The endocardium then secretes transforming growth factor beta family members, which act synergistically with bone morphogenetic protein-2 secreted by the myocardium, to increase mesenchyme formation and proliferation, which results in the growth of the endothelial cushions. The myocardial cells then invade the margins of the cellular endothelial cushions [13].

The semilunar valves form the division of the truncus arteriosus into two separate channels which form the aortic and pulmonary trunks.. The channels are created by the fusion of two truncal ridges across the lumen. In each channel a third swelling occurs opposite the first two which will form the 3rd leaflet. In the normal aortic valve the left and right leaflets of the adult valve are formed from the respective swellings while the posterior leaflet is formed from a swelling in the aortic trunk.

The pathogenesis of BAV is not yet fully understood. There is certainly a genetic component, especially given the association of BAV with other congenital abnormalities. However, fusion of the right and left valve cushions at the beginning ofvalvulogenesis appears to be a key factor in BAV formation [14].

A previous study suggested that BAV is a consequence of the anomalous behavior of cells derived from the neural crest because BAV often is associated with congenital aortic arch malformations and other neural crest-derived systems [15]. Other studies suggest that extracellular matrix proteins may affect the initiation of cell differentiation during valvulogenesis, while a molecular abnormality in this process may lead to the formation of abnormal cusps $[16,17]$. Some researchers suggest that a molecular abnormality in the extracellular matrix may lead to abnormal valvulogenesis, becouse matrix proteins help direct cell differentiation and cusp formation during valvulogenesis [16-18]. This could also explain why BAVis often linked to other cardiovascular anomalies.

These abnormalities cause the fusion of two cusps and lead to one larger cusp; therefore, the BAV usually includes two unequally sized cusps, the presence of a central raphe, and smooth cusp margin. A previous studies showed that raphal position was between the right and left cusp in $86 \%$ of cases [19]. An anomalous origin of coronary arteries depends on the 
spatial orientation of the two cusps. When the orientation of the cusps is anteroposterior, the coronary arteries originate from the anterior sinus or if cusps laterlateral oriented the right coronary artery originate from the common trunk and right Valsava's sinus [20].

A recent study has demonstrated that BAVs with fused right and noncoronary leaflets and those with fused right and left leaflets are different etiological entities. BAVs with fused right and noncoronary leaflets result from a morphogenetic defect that occurs before cardiac outflow tract septation on the basis of an exacerbated nitric oxide-dependent epithelialtomesenchymal transformation. On the other hand, BAVs with fused right and left leaflets result from anomalous septation of the proximal portion of the cardiac outflow tract, caused by dysfunctional neural crest cells [21].

The pulmonary valve can also be bicuspid, although this is much rarer and is most commonly associated with congenital heart disease such as Tetralogy of Fallot. There have been less than 10 cases reported in the literature of an isolated bicuspid pulmonary valve [22].

Deficient fibrillin-1 content in the vasculature of BAV patients may trigger matrix metalloproteinase production, thereby leading to matrix disruption and dilation. It has been noted that the fibrillin-1 content was remarkably reduced in the aorta of BAV patients, compared with that of patients with a tricuspid aortic valve. Aortic elasticity measurements of BAV patients suggest that diminished aortic elasticity is at least part of its causation [23-25].

\subsection{Anatomy}

The bicuspid valve is composed of two leaflets, of which one is usually larger (due to fusion of two cusps leading to one larger cusp), and unequal cusp size the presence of a central raphe (usually in the center of the larger of the two cusps). The raphe or fibrous ridge is the site of congenital fusion of the two components of the conjoined cusps and does not contain valve tissue (Figure 1) Three morphologies are identified: type 1, fusion of right coronary cusp and left coronary cusp; type 2, fusion of right coronary cusp and noncoronary cusp; and type 3 , fusion of left coronary cusp and noncoronary cusp. The most common is type 1 (70\% to $85 \%)$, followed by type $2(10 \%$ to $30 \%)$ and most rare type $3(1 \%)[13,19,26]$ (Figure 2$)$.

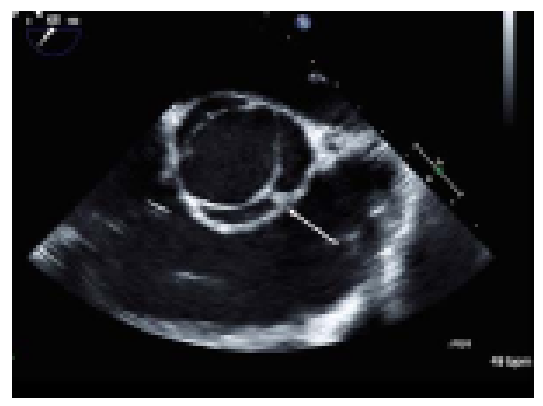

Figure 1. Transesophageal short-axis view of a BAV. There is fusion of the right and left cusps. The arrow points to the raphe. 


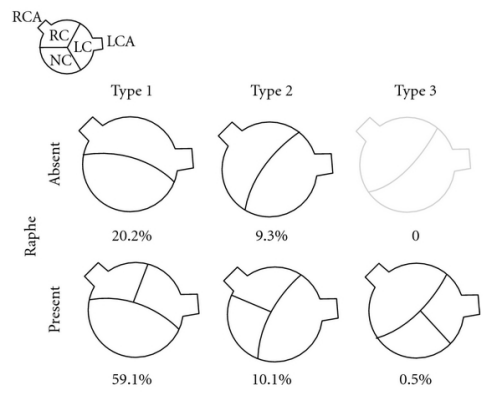

Figure 2. The classification and incidence of BAVs.

The site of cusp fusion can have e " ects on the prognosis of BAV [27], with the suggestion that type 1 BAVs are more likely to stenose as adults while type 2 valves will have complications at a younger age. The fused valve leaflet in BAV is actually smaller in area. Valvular incompetence is usually caused by the redundancy of one cusp, since the two cusps usually have different dimensions [28]

The coronary anatomy can be abnormal. Most patients with BAV disease have a left dominant coronary circulation [29]. This left coronary can arise from the pulmonary artery. The left main can also be up to $50 \%$ shorter than in normal in up to $90 \%$ of cases. This is an important consideration for any aortic valve surgery. The commonest abnormality associated with BAV is dilatation of the thoracic aorta, also known as aortopathy. This is thought not only to be due to the altered flow in the aorta, but also due to cellular structural abnormalities including decreased fibrillin, causing smooth muscle cell detachment, and cell death [30].

The other abnormality found in conjunction with BAV disease is coarctation of the aorta. $[22,31]$. The presence of coarctation and a poor result from repair can lead to more rapid failure of the valve or aortic dissection.

\subsection{Genetics}

$\mathrm{BAV}$ is an inheritable disorder, with a family recurrence rate of approximately $35 \%$ [33]. Recent clinical studies have reported a $9 \%$ prevalence of BAV in first-degree relatives of patients with BAV which was the estimated population prevalance of 1-2\% [33-35].

BAV is likely due to mutations in different genes with dissimilar patterns of inheritance [33].

The first genetic cause of BAV is Anderson syndrome, which is reported to be a result of mutations in the potassium channel gene KCNJ2 (chromosome 17q24.3)], whereas it clinically presents as ventricular arrhythmias, periodic paralysis, and scoliosis [36]. Another mutations in a gene called NOTCH1(gene map locus 9q34.3), a transmembrane receptor that has a role in determining cell outcome in organogenesis, were noted in two families with BAV [37]. Regions $18 q, 5 q$, and $13 q$ are reported to contain genes responsible for BAV and/or associated cardiovascular malformations [38,39]. The region 10q contains the ACTA2 gene, 
which encodes for smooth muscle alpha-actin (ACTA2), and mutation in this gene can result in thoracic aneurysm and, in some instances, BAV [40]. Also the ubiquitin fusion degradation 1-like gene UFD1L (chromosome 22q11.2) expressed in the outflow tract during embryogenesis is down-regulated in BAV tissue when compared with trileaflet valve tissue [41]. The UFD1L gene encodesa component of a multi-enzyme complex involved in the degradation of ubiquitin fusion proteins, and is highly expressed during embryogenesis in certain tissues. It seems to play a key role in the development of ectoderm-derived structures, including neural crest cells.Downregulation of the UFD1L gene, hypothetically resulting from an anomalous behavior of neural crest cells, may lead to reduced degradation activities, and may finally lead to fusion of valve cushions, a key factor in the development of congenital BAV[42]. Recent American College of Cardiology (ACC)/American Heart Association (AHA) adult congenital heart disease guidelines suggest echocardiographic screening for BAV and aortopathy in first-degree relatives of patients with BAV [43,44].

Although these valves are more common in males than females by a factor of 2:1 in the general population, the prevalance was equal in males and females in families having more than one affected individual $[45,46]$.

\section{Diagnosis}

Clinical findings are usually limited to auscultation with most patients having an ejection systolic murmur heard loudest at the apex [47]. The S1 usually is normal but sometimes may be associated with ejection click. The S2 is soft, and when aortic stenosis is present, S2 occurs simultaneously with P2. In aortic stenosis, an ejection systolic murmur is heard in the left second intercostal space but may also be transmitted to the carotid arteries. If aortic incompetence is present, a diastolic murmur of aortic regurgitation may be heard.

The electrocardiogram is usually normal; and ECG changes are not specific in patients with BAV: left ventricular hypertrophy, atrial enlargement, and arrhythmias may be present.

The mainstay of diagnosis is echocardiography (transthoracic or transoesophageal) which can provide a definitive diagnosis in the majority of patients [ $92 \%$ sensitivity and $96 \%$ specificity) $[48,49]$. Transesophageal echocardiography (TEE) is also very important for evaluating the aortic valve and thoracic aorta, whereas the sensitivity and specifity of multiplane technique for assessing aortic valve morphology is high [13].

The parasternal short axis view allows for direct visualization of the valve cusps. In this view the normal triangular opening shape is lost, becoming more "fish mouth-"like in appearance, more similar to the mitral valve. This is especially pronounced in systole, as in diastole the raphe can appear similar to a commissure of the third cusp. Differentiating severe bicuspid aortic stenosis from severe other aortic stenosis can also be difficult. In order to establish the diagnosis, the valve must be visualized in systole in the short-axis view. In the long-axis view, the valve often has an eccentric closure line and there is doming of the leaflets. If there is uncertainty in diagnosis, a TEE can improve visualization of the leaflets [50]. 
For BAV associated with stenosis, mean gradient and maximal flow velocity should be measured, but when regurgitation is present, the effective regurgitant area and Doppler jet size should be evaluated. For asymptomatic patients with aortic stenosis, echocardiography is recommended for evaluating disease progression. In asymptomatic patients, TTE recommended: every year for severe aortic stenosis, ever 1-2 years for moderate aortic stenosis and every 3-5 years for mild aortic stenosis [51].

In patients with poor acustic window, cardiac magnetic resonance (MRI) and multidetector computed tomography are useful for measuring the aortic valve area and is an alternative method to echocardiography in selected cases. MRI especially will enable views of the valve to be obtained without interference from calcification. It also allows for excellent assessment of the aorta. A recent study of 123 patients with confirmed BAV found that $10 \%$ of the patients were misidentified as having a tricuspid valve using transthoracic echo and $28 \%$ had a nondiagnostic study, in comparison to $4 \%$ being misidentified as having a tricuspid valve by MRI and $2 \%$ having a non-diagnostic study [52].

The current guidelines suggest that cardiac magnetic resonance imaging or cardiac computed tomography is reasonable in patients with BAVs when aortic root dilatation is detected by echocardiography to further quantify severity of dilatation and involvement of theascending aorta (Clas IIa; Level of Evidence: B)[53].

\section{Clinic}

The clinical presentation of patients with BAV can vary from severe valve disease in infancy to asymptomatic valve disease in old age. It may be associated with abnormalities of the aortic wall such as coarctation of the aorta, aortic dissection, and aortic aneurysm. Most patients with a BAV develop some complications during life [1,2].

Congenital coronary anomalies, coronary atherosclerosis, and calcification have been described in association with BAV[3].

The congenitally BAV may function normally throughout life, may develop progressive calcification and stenosis or may develop regurgitation with or without infection. Aortic root dilatation is common in BAV, even when the valve is haemodynamically normal, and consequently aortic dissection usually occurs in previously asymptomatic patients [4,5].

Sudden death may occur as a result of obstruction of the left ventricular outflow tract by a congenital BAV [54]. BAV are in most cases remain undetected until infection or calcification supervenes [55].

Aortic stenosis and regurgitation, infective endocarditis and aortic dissection are the most common complications. Left coronary artery dominance is more common in patients with a BAV (29-56.8\%) and in $90 \%$ of cases, the left main coronary artery is less than $5 \mathrm{~mm}$ in length $[7,8]$. The ignorance of these associations may cause an inadequate myocardial preservation and an increased risk of myocardial infarction $[9,10]$. 
Symptoms associated with aortic stenosis are angina pectoris, syncope, and congestive heart failure. The most common complication of aortic stenosis is congestive heart failure symptomatically presented with dyspnea, which is a result of combined diastolic and systolic dysfunction [56]. Angina pectoris occurs in patients with severe aortic stenosis and in those who do not have coronary artery disease; it may be a result of ventricular hypertrophy.

Syncope is another common symptom in patients with BAV. Syncope reflects the cerebral hypoperfusion caused by the inability to increase stroke volume during physical activity.

The clinical presentation in patients with BAV and presence of other cardiac congenital defects depends from structural complexity of the heart. In patients with interventricular septal defects, the clinical presentation depends on the size of the defect area and the grade of aortic stenosis. If the interventricular defect is small, the patient may be asymptomatic, but when the interventricular defect is large, cardiac output will decrease and Eisenmenger syndrome will develop.

Two large recent series reported that clinical course of unoperated patients with BAV depends on age, stenosis, and aortic incompetence. The severe aortic stenosis, and severe aortic incompetence in older patients increases the risk of primary cardiac events including cardiac death. Both these studies suggest that intervention on the basis of early symptoms or incipient cardiac dysfunction may decreases the mortality of patients with BAV $[57,58]$.

The natural history of BAV has been evaluated several cohort studies. It is known to be variable and of course somewhat dependent on associated abnormalities. It can range from severe aortic stenosis in childhood to asymptomatic disease until old age. There have indeed been incidental findings of a minimally calcified BAV in patients in their 70s.More commonly however [in around $75 \%$ of patients] there is progressive fibrocalcific stenosis of the valve eventually requiring surgery. This usually leads to presentation in middle age only around $2 \%$ of children have clinically significant BAV disease [59].

The prevalence of fibrosis, cystic medial necrosis, elastic fragmentation, and inflammation has been shown to be significantly higher in patients with fusion of the left coronary and right coronary cusps. fusion of the left coronary and right coronary cusps was associated with a larger aortic root diameter and a smaller aortic arch,than was fusion of the right coronary and non-coronary cusps. Another study demonstraed that fusion of the right coronary and non-coronary cusps correlated with the more rapid growth of ascending aortic diameter in the pediatric population [60-63].

There have been a couple of studies looking at long-term followup of patients with unoperated BAV. A cohort of 212 asymptomatic patients with BAV were found to have the same 20-year survival rate as the normal population but an increased frequency of cardiac events including aortic valve surgery, ascending aorta surgery and any other cardiovascular surgery. Predictive factors for cardiovascular events were found to be age $\geq 50$ years and valve degeneration at diagnosis while baseline ascending aorta $\geq 40 \mathrm{~mm}$ independently predicted surgery for aorta dilatation. Another study [64] 642 patients were followed up for a mean of 9 years, again with a 10-year survival rate similar to the normal population [96\%]. One or more primary cardiac events occurred in $25 \%$ including cardiac death in 3 , intervention on 
aortic valve or ascending aorta in $22 \%$, aortic dissection or aneurysm in $2 \%$, and congestive heart failure requiring hospital admission in $2 \%$. Independent predictors of primary cardiac events were age older than 30 years, moderate or severe aortic stenosis, and moderate or severe aortic regurgitation [50].

In the another study [61].the incidence of aortic dissection was found to be $1.5 \%$ in all patients regardless of the progression of BAV; however this increased markedly in patients aged 50 or older at baseline to $17.4 \%$ and even more in those found to have aneurysm formation at baseline to [44.9\%]. 25-year rate for aortic surgery was $25 \%$ and there was a significant burden of progression of disease to cause aortic dissection with 49 of the 384 patients without baseline aneurysms developing them during followup [22].

Although the clinical presentation of patients with BAV can vary from severe valve disease in infancy to asymptomatic valve or thoracic aortic disease in old age, symptomstypically develop in adulthood. The clinical manifestations relate to the function of the aortic valve,the aortopathy/dissection, and acquired complications such as endocarditis. However in childhood, BAV disease is commonly asymptomatic [61]

Estimates of late cardiac events were approximately $25 \%$ at a mean age of 44 years in the study from Toronto and $40 \%$ at a mean age of 52 years in the Olmsted County study $[62,63]$. In the Olmsted County series, $27 \%$ of adults with BAV and no significant valve disease at baseline required cardiovascular surgery within 20 years of follow-up. Twenty-two percent of the patients in the Toronto cohort required intervention within 9 years of follow-up. In both studies, age was an important determinant of outcomes supporting the notion held by many that eventually most patients with BAV would require some form of intervention.

\subsection{Aortic stenosis}

A common complication of BAV disease is aortic stenosis. BAV is recognized as a frequent cause of aortic stenosis in adults. Aortic stenosis has been found in $72 \%$ of adults with BAV. In 388 patients with severe aortic valve disease alone, BAVs were found in $45 \%$ of the patients with aortic stenosis and $24 \%$ of the patients with aortic regurgitation. In 110 patients with severe combined aortic and mitral valve disease, BAVs were found in only $12 \%$ [64].

Among the 600 patients analyzed, 213 (36\%) had pure aortic stenosis, 265 (44\%) had pure aortic regurgitation and $122(20 \%)$ had combined stenosis and regurgitation. BAVs represented $18 \%$, as the third most important cause of aortic disorder following degenerative and rheumatic changes, followed by infective endocarditis (5\%) [65].

The main symptoms are exertional dyspnea, syncope, and chest pain. These patients should be evaluated and managed similarly to patients with tricuspid aortic valve stenosis.

In the Joint Study of the Natural History of Congenital Heart Defects, one-third of the children in the cohort had increases in catheterization gradients during the 4- to 8-year followup period. In the follow-up study, children with baseline peak left ventricular to aortic gradients $>50 \mathrm{~mm} \mathrm{Hg}$ were at risk for serious cardiac events at a rate of $1.2 \%$ per year. In theUnited Kingdom cohort. $20 \%$ of children with mild aortic stenosis at baselinehad mild 
disease after 30 years of follow-up. Age was the primary determinant of valvular disease progression $[50,66]$.

In adults, with BAV, stenosis occurs by similar methods to the process in patients with tricuspid aortic valves. It is felt to be due to calcification, endothelial dysfunction, inflammation, lipoprotein deposition, and ossification of the aortic side of the valve leaflets. There has been a suggestion that leaflet orientation may be a predictive factor in the rate of valve stenosis. The folding and creasing of the valves and the turbulent flow are felt to contribute to development of fibrosis and calcification [59].more rapid progression in aortic valve gradients occurred in patients with anteroposteriorly located cusps[60]. However, not all studies have found this association, and the 2 large studies in adults have not identified leaflet orientation as a risk factor for late adverse events. Olmsted County study identified a composite index of valve degeneration, which incorporated valve thickening, calcification, and mobility, that was an independent predictor of long-term cardiac events in a population of adults with no baseline valve dysfunction. The predictive role of both morphology and function in adults with BAV parallels that observed in series examining older adults with aortic stenosis mostly of acquired basis $[50,62,63]$.

\subsection{Aortic incompetence}

Primary aortic regurgitation without infective endocarditis was uncommon, and $32 \%$ had an apparently normally functioning aortic valve [67].

One cohort of $118 \mathrm{BAV}$ patients found that of 70 patients without aortic stenosis, 28 (40\% had moderate to severe aortic regurgitation. The mechanisms of aortic incompetence in children are usually due to prolapsing cusps, myxoid degeneration, postvalve surgery and after balloon valvuloplasty or endocarditis, while as the patients age dilatation of the ascending aorta can lead to a functionally regurgitant valve[68,69]. With age, aortic incompetence may also develop secondary to dilation of the ascending aorta. In the Olmstead study of asymptomatic adults, $47 \%$ had some degree of aortic incompetence at baseline; however, interventions for severe aortic incompetence were relatively uncommon, occurring in only $3 \%$ of the cohort during follow-up. In the Toronto study $21 \%$ of the population had moderate or severe aortic incompetence at baseline; however, only $6 \%$ had an intervention for symptomatic aortic incompetence or progressive left ventricular dysfunction $[62,63]$.

\subsection{Aortopathy/aortic dissection}

BAV patients tend to develop vascular abnormalities of the aorta, such as dilation, coarctation and dissection. Aortic dilation in BAV patients is thought to be caused by intrinsic aortic disease that is characterized by cystic medial necrosis and disruption of the extracellular matrix due to fibrillin deficiency. BAV is often associated with dilatation of the aortic root and the ascending aorta. This is otherwise known as aortopathy. This can lead to aneurysm and dissection. The dilatation has been reported during childhood, and it has also been suggested that increased aortic size at baseline is predictive for earlier dilatation and worse outcomes. Aortic size is larger generally in patients with BAV compared to those with normal 
valves. The most likely risk factor for progression is felt to be age. Aortic root size itself is related to valve morphology and the presence of significant disease [22,6]; however, a recent study did suggest that while most patients with BAV and ascending aortic aneurysm had severe valve dysfunction, there was a small proportion of patients $(5 \%)$ who did have aneurysm formation without any aortic valve dysfunction [50].

In the ascending aorta as well as the pulmonary trunk, the severity of cystic medial necrosis, elastic fragmentation and changes in the smooth muscle cell orientation have been found to be significantly more severe in patients with bicuspid valves than in those with tricuspid valves.

Factors leading to aortic dissection four years after the Bentall operation have been considered to be an impact of congenital BAV or proximal anastomosis of venous grafts, or both [70].

Studies have suggested that patients with BAV have an intrinsic defect in the aortic wall that results in aortic disease, regardless of aortic valve function. BAV was associated with significantly less intimal change, and less fragmentation and loss of elastic tissue, compared with patients with a tricuspid aortic valve. Type I and III collagens were significantly decreased in dilated aortas of BAV patients, compared with controls, particularly at the convexity. Expression of messenger RNA [ribonucleic acid] for collagens was lower than normal only in the regurgitant subgroup. Fewer smooth muscle cells and greater severity of elastic fiber fragmentation were observed at the convexity than at the concavity [71-73].

Among 119 cases of fatal dissecting aneurysm of the aorta, 11 cases of congenital BAV (9\%) were observed. Among the latter, three had coarctation of the aorta and one had Turner's syndrome without coarctation. In each case, cystic medial necrosis of the aorta was present. Hypertension was either established or inferred from cardiac weight in $73 \%$ of the cases. The high incidence among subjects with dissecting aneurysm suggested a causative relationship between BAV and aortic dissecting aneurysm [74].

Many theories have been postulated for the mechanism of BAV aortopathy. For a long time there has been felt to be a genetic component; however there is increasing evidence for a haemodynamic mechanism. It is felt that it is due to defects in the aortic media, such as elastin fragmentation, loss of smooth muscle cells, and an increase in collagen [6,22]. Systemic features have also been noted in BAV patients which may predispose to aneurysm formation including systemic endothelial dysfunction and higher plasma levels of matrix metalloproteinases [75].

Pathological examination of surgical specimens from the aortic wall of patients with aortic dissection associated with BAV showed cystic medial necrosis or mucoid degeneration [76].

Matrix metalloproteinases (endogenous enzymes that degrade matrix components) have been implicated in atherosclerotic aortic aneurysm formation and appear to be elevated in the aorta of patients with BAVs [77].

The histological findings of BAV are nonspecific, and had been described by several authors in patients with Marfan syndrome [78-80]. The histopathological appearance of thoracic aortic aneurysm in Marfan and BAV is similar, and includes evidence of vascular smooth 
muscle cell (VSMC) apoptosis and extracellular matrix degeneration in the absence of a significant inflammatory response [81].

Abnormalities in the ascending aorta of the patients with BAV, specifically premature medial layer VSMC apoptosis, have been described, explaining the higherthan-expected prevalance of aortic dissection in these patients [82].

Also recently studies show less elastic tissue in the aortas of BAV patients $[83,84]$.

In patient with BAV there are fibrillin, fibronectin, and tenascin abnormality. Additionally Bonderman et al suggested that a primary role for VMSC apoptosis in the development of aneurysm these patients [85].

The FBN1 gene encodes fibrillin-1, a large glycoprotein that is secreted from cells and deposited in the extracellular matrix in structures called microfibrils. Microfibrils are found at the periphery of elastic fibers, including the elastic fibers in the medial layer of the ascending aorta, and in tissues not associated with elastic fibers.

The histopathological appearance of thoracic aortic aneurysm in Marfan and BAV is similar, and includes evidence of VSMC apoptosis and extracellular matrix degeneration in the absence of a significant inflammatory response. Abnormalities in the ascending aorta of the patients with BAV, specifically premature medial layer smooth muscle cell apoptosis, have been described, explaining the higherthan-expected prevalance of aortic dissection in these patients [82,83].

Aortic root dilation has been documented in childhood, suggesting that this process begins early in life. Furthermore, children with BAV have greater increases in aortic dimensions than do children with trileaflet valves. In both children and adults, progressive dilation of the aorta is more common in patients with larger aortas at baseline. In BAV disease, the aortic annulus, sinus, and proximal ascending aorta are larger than those found in adults with trileaflet valves [50].

In the Olmsted County study, the prevalence of ascending aorta dilation ( $>40 \mathrm{~mm}$ ) was $15 \%$ and in the subset of patients with repeat measurements, the prevalence increased to $39 \%$ at study completion. Dilation of the ascending aorta was an independent risk factor for ascending aorta surgery. Although there are a number of risk factors associated with dilation of the ascending aorta including increased systolic blood pressure, male sex, and significant valve disease, the most important variable is likely age $[50,63,64]$. Aortic root size is shown to be related to valve morphology and the presence of significant valve disease. In the Toronto series, the prevalence of dissection was $0.1 \%$ per patient-year of follow-up, and in the Olmsted County study, there were no cases of dissection. Despite the low rates of dissection, the increasedprevalence of BAV disease relative to Marfan syndrome make dissections due to BAV equal to or more common than dissections due to Marfan syndrome [86]. Dissection in BAV, when it occurs, typically involves the ascending aorta, but involvement of the descending aorta has been reported in older patients. Although dissection is more common in patients with dilated aortas, there are reports of dissection in normal-sized aortic roots and after valve replacement. Risk factors for dissection have included aortic size, aortic stiffness, male sex, family history, and the presence of other lesions such as coarctation of the aorta or Turner syndrome [50]. 


\subsection{Endocarditis}

Endocarditis is more common in BAV. The estimated incidence is $0.16 \%$ per year in unoperated children and adolescents [87]. In adults the case series by Michelena give an incidence of $2 \%$ per year [56].

Outcomes in BAV patients with infective endocarditis tend to be worse than in those with normal valves. A recent study of 310 patients with infective endocarditis found that the 50 patients with BAV were younger at presentation and had a higher incidence of aortic perivalvular abscess. In-hospital mortality and 5-year survival were also comparable to patients with normal valves [22].

Most patients are unaware of their condition until the onset of infective endocarditis

Patients with BAV endocarditis are young, and there is strong male predominance. Staphylococci and viridans streptococci account for nearly three-quarters of the cases affecting BAVs. Endocarditis can lead to severe acute aortic incompetence, heart failure and it is poorly tolerated [88].

Endocarditis risk was estimated to range between $2 \%$ or $0.3 \%$ year. Because the risk of endocarditis is felt to be low, the ACC/AHA practice guidelines no longer suggest bacterial endocarditis prophylaxis in patients with straightforward BAV disease, except in patients with a prior history ofendocarditis [50,89].

\subsection{Coronary artery disorders}

Some reports have also suggested that the involvement of coronary arteries, including congenital coronary artery anomalies, coronary artery fistulas, spontaneous coronary artery dissection, immediate bifurcation and a shorter length of the left main coronary artery $[6,13]$. The incidence of left dominance in BAVs has been found to be unusually high (24.4-56.8\%), compared with the incidence in tricuspid valves [9.5\%]. Patients with BAVs have higher incidence of immediate bifurcation of the left main coronary artery, and higher incidence of left main coronary length less than $10 \mathrm{~mm}$. The mean length of the left main coronary artery is significantly shorter in BAV patients [90].

Anomalous origins of the right 20,21 and left 22 coronary arteries, association with annuloaortic ectasia, and anomalous origins of the left circumflex coronary artery 23 and single left coronary artery, 24 have been noted in patients with BAVs. Spontaneous coronary artery dissection may occur in BAV patients [91]

There have also been some case reports describing patients with BAVdisease associated with coronary heart disease [92] and even with acute myocardial infarction[10].

Also Recently studies[93]Yuan et al. suggested that the prevalence rate of angiographic coronary heart disease was higher among the patients with BAVdisease.

\subsection{Congenital heart defects}

Patent ductus arteriosus and ventricular septal defect are the most frequent congenital heart defects associated with BAV. Patent ductus arteriosus is usually present in pediatric patients 
with BAV and may be associated with hand anomalies. BAV is reported to be present in up to $30 \%$ of adult patients with small ventricular septal defects. However, BAV may also be associated with large ventricular septal defects and poor clinical outcome. There is significantly higher incidence of aortic arch obstruction (51.1\%). The frequency of BAV in specimens with complete transposition of great arteries has been found to be $1 \%[13,50]$.

Hypoplastic left heart syndrome, complete atrioventricular canal defect, Ebstein's anomaly, partial or total anomalous pulmonary venous return, tetralogy of Fallot, double-outlet right ventricle, septal left ventricular diverticulum,Williams syndrome,Down syndrome and annuloaortic ectasia are occasionally associated with BAV. Shone's complex, which is defined by four cardiovascular defects including supravalvular mitral membrane, valvular mitral stenosis with a parachute mitral valve, subaortic stenosis and aortic coarctation, is a rare entity and forms another association in BAV cases [94].

It has been reported that BAV is presented in $>50 \%$ of patients with coarctation of the aorta [COA]. Patients with COA and BAV are reported to have more severe disease associated with aortic stenosis, aortic regurgitation, and aortic aneurysm. The risk of dissection of the aorta and death is greater when COA and BAV are comorbid.

Turner syndrome characterized by a defect in or the absence of one $\mathrm{X}$ chromosome. Except for gonadal dysgenesis, cardiovascular defects are commonly present in this group of patients. Clinical research on patients with Turner Syndrome reports that BAV is present in $30 \%$ of cases, that over $95 \%$ of BAV s result from fusion of the right and left coronary leaflets, and that aortic ascending diameters are significantly greater in this group of patients [13].

\subsection{Thromboembolism}

Thrombus formation in a native BAV is a rare complicaton. Pathological studies have indicated that post-inflammatory changes ocur in the resected BAV, which is prone to develop thrombosis on the valve surface or in the calcification area [95].

Microthrombus formation and valve thickening with incompetence could result in embolization, and subsequent cerebrovascular events [96].

Embolization from calcific BAVs may lead to stroke and myocardial infarction. Conservative management with anticoagulation, to treat associated post-stagnation thrombosis, or aortic valve replacement as the treatment, is debatable [97].

\section{Management}

\subsection{Medical}

Medical therapies are to try and alleviate symptoms and slow progression. It is generally felt that blood pressure should be aggressively controlled to try and slow the progression of aortopathy [51]. 
High blood pressure should be aggressively treated in patients with BAV disease. In Marfan-associated aortopathy, treatment with beta-blockers to slow the rate of progression is the standard of care at many centers, although debate exists about their effectiveness [50,101]. The ACC/AHA guidelines for the management of adult congenital heart disease and guidelines for the management of patients with valvular heart disease suggest that it is reasonable to use beta-blockers in this population [Class IIa recommendation] [53]. There are emerging data in animal models and in 1 small study in humans supporting the use of angiotensin II receptor blockers to decreased aortic root dilation in Marfan syndrome [50]. Whether these agents will have a role in BAV aortopathy has not yet been demonstrated. Also long-term vasodilator therapy in BAV disease with aortic regurgitation is only recommended if there is concomitant systemic hypertension [47]. The relationship between risk factors for atherosclerosis and the development and progression of degenerative aortic valve disease has been well studied [99]. However, the role of treatment with cholesterol-lowering agents is unresolved. The use of lipid lowering agents specifically in young patients with BAV has not been studied, and the current ACC/AHA guidelines for the management of patients with valvular heart disease do not endorse the use of statins to slow the degenerative process in this population [51]. Concomitant conditions and risk factors should be treated as in the normal population.

\subsection{Surgical}

Indications for valve surgery in patients with BAV are similar to those with tricuspid aortic valve disease or degenerative aortic valve disease [100].

The 2006 AHA/ACC guidelines also suggest concomitant replacement of the ascending aorta if it is greater than $45 \mathrm{~mm}$ in diameter [51]. Estimated 15-year freedom from complications was $86 \%$ in patients with an aortic diameter less than $40 \mathrm{~mm}$, dropping down to $81 \%$ in those with diameter $40-44$ and $43 \%$ in patients with a diameter $45 \mathrm{~mm}$ or greater.

When rheumatic disease is excluded, a significant portion of adults undergoing surgery for aortic valve disease will have a congenitally malformed valve. During childhood, insertion of a prosthetic valve is suboptimal because of the continuing growth of the child. Fortunately, at this stage, the aortic valve is usually not calcified and valvuloplasty can successfully disrupt the commissural fusion and relieve obstruction. Valvuloplasty is the interventional strategy of choice in children and in some young adults with BAV and aortic stenosis. Symptomatic aortic stenosis is an indication for intervention, similar to standard indications for trileaflet valve disease. However, in the pediatric setting, indications include children with peak-topeak gradients $>50 \mathrm{~mm} \mathrm{Hg}$ who develop symptom at rest or with exercise. An additional indication includes asymptomatic children with peak-to-peak gradients $>60 \mathrm{~mm}$ $\mathrm{Hg}$. In adulthood, aortic valve replacement is the most common intervention for either aortic valve stenosis or incompetence, and valvuloplasty is rarely performed [50,51,62].

BAV disease involves younger patients and involves both the valves and the ascendan aorta; therefore, surgical decision making is more complicated. Approximately $30 \%$ of adults undergoing aortic valve replacement will also need aortic root surgery[63]. The guideline suggest that a cutoff of $5.0 \mathrm{~cm}$ be used for intervention or $4.5 \mathrm{~cm}$ if the surgery is otherwise 
being performed for valve indications. In addition, suggest that changes in root size more than $0.5 \mathrm{~cm} /$ year are an indication for root replacement [53].

Recently published Guidelines [53] for the diagnosis and management of patients with thoracic aortic disease recommendations for BAV are summarized below:

\section{CLASS I}

1. First-degree relatives of patients with a BAV, premature onset of thoracic aortic disease with minimal risk factors, and/or a familial form of thoracic aortic aneurysm and dissection should be evaluated for the presence of a BAV and asymptomatic thoracic aortic disease. (Level of Evidence: C)

2. All patients with a BAV should have both the aortic root and ascending thoracic aorta evaluated for evidence of aortic dilatation (Level of Evidence: B)

3. Should undergo elective operation at smaller diameters $(4.0$ to $5.0 \mathrm{~cm})$ to avoid acute dissection or rupture. ()Level of Evidence: C)

4. Patients with a growth rate of more than $0.5 \mathrm{~cm} /$ year in an aorta that is less than $5.5 \mathrm{~cm}$ in diameter should be considered for operation. (Level of Evidence: C)

5. Patients undergoing aortic valve repair or replacement and who have an ascending aorta or aortic root of greater than $4.5 \mathrm{~cm}$ should be considered for concomitant repair of the aortic root or replacement of the ascending aorta. (Level of Evidence: C)

6. Elective aortic replacement is reasonable for patients with BAV when the ratio of maximal ascending or aortic root area $(\pi \mathrm{r} 2)$ in $\mathrm{cm} 2$ divided by the patient's height in meters exceeds 10 (CLASS IIa, Level of Evidence: C).

In regard to valve surgery, there is controversy regarding the use of the Ross procedure and the use of valve repairs in this population. Abnormalities of the media are seen in both the aorta and the pulmonary artery in BAV disease. Intrinsic abnormalities in the wall of the pulmonary artery [neoaorta] may contribute to progressive neoaortic root dilation and/or aortic regurgitation when the pulmonary root is placed in the systemic position [101].

When to surgically treat asymptomatic patients with BAV remains controversial. The risk of sudden death in asymptomatic adult patients with severe aortic stenosis is reported to be less than $1 \%$ per year, however, current practice guidelines recommended aortic valve replacement in patients with reduced left ventricular systolic function $(\mathrm{EF}<50 \%)$ without other explanation even when they are asymptomatic [51].

For high-risk patients to undergo conventional novel methods including aortic balloon valvulotomy or transfemoral valve implantation may be helpful. A patient considered inoperable should be treated orally with angiotensin converting enzyme (ACE) inhibitors, diuretics, and digitalis. In patients with depressed LV associated with pulmonary congestion and atrial fibrillation, diuretics and digitalis may be used with the understanding that in some cases intensive hemodynamic monitoring is needed. Patients with aortic root dilatation $>4.0 \mathrm{~cm}$ who are not candidate for surgical treatment should be given $\beta$-adrenergic blocking agents [51]. 


\subsection{Pregnancy}

During pregnancy there are changes in hemodynamics as well as changes in the aortic media, and therefore, women with BAV and significant aortic stenosis and/or dilated aortic roots are at risk for complications during pregnancy.

In rare instances, women will develop progressive symptoms during pregnancy and require either valvuloplasty or valve surgery. Both interventions can be performed during pregnancy, but are associated with both maternal and fetal risks and should be performed only when necessary.

Although pregnancy can be successfully completed in most instances, aortic surgery may be required early after pregnancy in some women with severe aortic stenosis. Pregnancy itself seems to accelerate the need for surgery postpartum in women with moderate or severe aortic stenosis, perhaps by affecting the ability of the left ventricle to adapt to the fixed outflow obstruction. It is therefore important that women be counseled about both the risk of pregnancy and the potential for late complications [102,103].

Additionally, guidelines suggest that women with BAV and significant aortopathy (ascending aorta diameter $>4.5 \mathrm{~cm}$ ) "should be counseled against the high risk of pregnancy" [43].

\subsection{Exercise}

There are little data available to support recommendations regarding exercise in subjects with BAV. In children with congenital severe aortic stenosis, for instance, sudden death can occur during exercise [121]. The Task Force on Exercise in Patients with Heart Disease recommends that athletes with severe aortic stenosis or severe aortic incompetence with left ventricular dilation [left ventricular dimensions $>65 \mathrm{~mm}$ ] should not participate in competitive athletics. Athletes with or without aortic valve disease who have dilated aortic roots $(>45 \mathrm{~mm})$ are advised to only participate in low-intensity competitive sports. No restrictions exist for those with BAV with no significant valve dysfunction or aortic root/ascending aorta dilation $(>40 \mathrm{~mm})[50,104,105]$.

\section{Conclusions}

Consequently aortic stenosis and regurgitation, infective endocarditis and aortic dissection are the most common complications of BAV additionaly this process continues after valve replacement. The person with BAV requires continuous surveillance to treat associated lesions and prevent complications. Arterial hypertension should be meticulously controlled. Smoking should be discouraged and control of hypercholesterolaemia considered, in view of the impact of these factors on the development of aortic stenosis. Aortic root dilatation is common in BAV, even when the valve is haemodynamically normal, and consequently aortic dissection usually occurs in previously asymptomatic patients. Beta-blockers and statins are the possibilities for medical treatment, and aortic valve repair/replacement and ascending aorta replacement are indicated for patients with a severely diseased aortic valve and 
aorta. All patients should therefore be regularly reviewed to identify progressive root dilatation $[6,94]$.

\section{Author details}

Mehmet Demir

Bursa Yüksek İhtisas Education and Research Hospital, Cardiology Department, Bursa, Turkey

\section{References}

[1] Braverman AC, Güven H, Beardslee MA, et al.The bicuspid aortic valve. Curr Probl Cardiol 2005;30:470-522.

[2] Yener N, Oktar GL, Erer D, et al. Bicuspid aortic valve. Ann Thorac Cardiovasc Surg. 2002 Oct;8[5]:264-7.

[3] Ward C. Clinical significance of the bicuspid aortic valve. Heart 2000; 83: 81-5.

[4] Tadros TM, Klein MD, Shapira OM. Ascending aortic dilatation associated with bicuspid aortic valve: pathophysiology, molecular biology, and clinical implications Circulation. 2009 17;119[6]:880-90.

[5] Pachulski RT, Weinberg AL, Chan KL. Aortic aneurysm in patients with functionally normal or minimally stenotic bicuspid aortic valve. Am J Cardiol 1991; 67:781-2.

[6] Demir M. Current Approach to Bicuspid Aortic Valve: Review. Global Advanced Research Journal of Medicine and Medical Sciences. 2012: 1[5]; 105-107.

[7] Hutchins GM, Nazarian IH, Bulkley BH. Association of left dominant coronary arterial system with congenital bicuspid aortic valve. Am J Cardiol 1978; 42: 57-9.

[8] Higgins CB, Wexler L. Reversal of dominance of the coronary arterial system in isolated aortic stenosis and bicuspid aortic valve. Circulation 1975; 52: 292-6.

[9] Presbitero P, Demarie D, Villani M, et al. Long term results [15-30 years] of surgical repair of aortic coarctation. Br Heart J 1987; 57: 462-7.

[10] Demir M. Acute myocardial infarction in a young patient with bicuspid aortic valve. Turk Kardiyol Dern Ars. 2009 Oct;37[7]:490-2.

[11] Suzuki T, Nagai R, Kurihara H, et al. Stenotic BAVassociated with a ventricular septal defect in an adult presenting with congestive heart failure: a rare observation. European Heart Journal. 1994;15:402-403. 
[12] Rabkin-Aikawa E, Farber M, Aikawa M,et al. Dynamic and reversible changes of interstitial cell phenotype during remodeling of cardiac valves. The Journal of heart valve disease 2004; 13:841-847.

[13] Blerim Berisha, Xhevdet Krasniqi,Dardan Kocinaj, Ejup Pllana and Masar Gashi Bicuspid Aortic Valve.In: Ying-Fu Chen and Chwan-Yau Luo. (ed) Aortic valve. Rijeka: InTech; 2011.

[14] Sans-Coma V, Fernández B, Durán AC, et al. Fusion of valve cushions as a key factor in the formation of congenital bicuspid aortic valves in Syrian hamsters. Anat Rec. 1996;244[4]:490-8.

[15] Kappetein AP, Gittenberger-de Groot AC, Zwinderman AH, et al. The neural crest as a possible pathogenetic factor incoarctation of the aorta and bicuspid aortic valve. The Journal of Thoracic and Cardiovascular Surgery 1991; 102[ 6]:830-836.

[16] Eisenberg LM, Markwald RR. Molecular regulation of atrioventricular valvuloseptal morphogenesis. Circulation Research, 1995; 77[ 1]: 1-6.

[17] Fedak PW, Verma S, DavidTE,et al. Clinical and pathophysiological implications of a bicuspid aortic valve. Circulation 2002;106:900-4.

[18] Hinton RB, Jr, Lincoln J, Deutsch GH, et al. Extracellular matrix remodeling and organization in developing and diseased aortic valves. Circulation Research 2006; 98[11]:1431-1438.

[19] Sabet HY, Edwards WD, Tazelaar HD, et al. Congenitally bicuspid aortic valves: a surgical pathology study of 542 cases [1991 through 1996] and a literatüre review of 2715 additional cases. Mayo Clinic Proceedings 1996;74[1]:14-26.

[20] Schang SJ, Pepine CJ, Bemiller CR, et al. Anomalous coronary artery origin and bicuspid aortic valve. Vasc Surg 1975; 9: 67-72.

[21] Fernández B, Durán AC, Fernández-Gallego T, et al. Bicuspid aortic valves with different spatial orientations of the leaflets are distinct etiological entities. J Am Coll Cardiol.2009;54[24]:2312-8.

[22] Ify Mordi, Nikolaos Tzemos. BAVDisease: A Comprehensive Review. Cardiology Research and Practice 2012];

[23] Leme MP, David TE, Butany J, et al. Molecular evaluation of the great vessels of patients with BAVdisease. Rev Bras Cir Cardiovasc. 2003;18[2]:148-56.

[24] Sá MPL, Bastos ES, Murad H. Valva aórtica bicúspide: fundamentos teóricos e clínicos para substituição simultânea da aorta ascendente [Bicuspid aortic valve: theoretical and clinical aspects of concomitant ascending aorta replacement]. Rev Bras Cir Cardiovasc.2009;24[2]:218-24.

[25] Yap SC, Nemes A, Meijboom FJ, et al. Abnormal aortic elastic properties in adults with congenital valvular aortic stenosis. Int J Cardiol. 2008;128:336-41. 
[26] Fernandes SM, Sanders SP, Khairy P, et al. Morphology of BAVin children and adolescent. Journal of the American College of Cardiology 2004;44[8]:1648-1651.

[27] T. J. Calloway, L. J. Martin, X. Zhang, et al. "Risk factors for aortic valve disease inbicuspid aortic valve: a family-based study," American Journal of Medical Genetics 2011;155[5]:1015-1020.

[28] De Mozzi P, Longo UG, Galanti G, et al. Bicuspid aortic valve: a literature review and its impact on sport activity. British Medical Bulletin 2008;85:63-85.

[29] W. C. Roberts. The congenitally bicuspid aortic valve. A study of 85 autopsy cases. The American Journal of Cardiology 1970;26[1]:72-83.

[30] E. S. Murphy, J Rosch, S. H. Rahimtoola. Frequency and significance of coronary arterial dominance in isolated aortic stenosis. American Journal of Cardiology 1977;39[4]: 505-509.

[31] B. Stewart, R. Ahmed, C. M. Travill,et al. Coarctation of the aorta life and health 2044 yers after surgery repair. British Heart Journal 1993;69[1]:65-70.

[32] Larson EW, Edwards WD. Risk factors for aortic dissection: a necropsy study of 161 cases. Am J Cardiol 1984;53:849-55.

[33] Cripe L, Andelfinger G, Martin J, Shooner K, Benson DW. BAVis heritable. J Am Coll Cardiol 2004;44:138-43.

[34] Huntington K, Hunter AG, Chan KL. A prospective study to assess the frequency of familial clustering of congenital bicuspid aortic valve. J Am Coll Cardiol 1997;30:1809-12.

[35] Glick BN, Roberts WC. Congenitally BAVin multiple family members. Am J Cardiol 1994;73:400-4.

[36] Andelfinger G, Tapper AR, Welch RC, et al. KCNJ2 mutation results in Andersen syndrome with sex-specific cardiac and skeletal muscle phenotypes. American Journal of Human Genetics 2002;71[3]:663-668.

[37] Garg V, Muth AN, Ransom JF, et al. Mutations in NOTCH1 cause aortic valve disease. Nature 2005;437:270-4.

[38] Mohamed SA, Aherrahrou Z, Liptau H, et al. Novel missense mutations [p.T596M and p.P1797H] in NOTCH1 in patients with bicuspid aortic valve. Biochem Biophys Res Commun 2006;345:1460-5.

[39] Martin LJ, Ramachandran V, Cripe LH, et al. Evidence in favor of linkage to human chromosomal regions $18 \mathrm{q}, 5 \mathrm{q}$ and $13 \mathrm{q}$ for BAVand associated cardiovascular malformations. Hum Genet 2007;121:275-84.

[40] Guo DC, Pannu H, Tran-Fadulu V, et al. Mutations in smooth muscle alpha-actin [ACTA2] lead to thoracic aortic aneurysms and dissections. Nat Genet 2007;39:148893. 
[41] Mohamed SA, Hanke T, Schlueter C, et al.Ubiquitin fusion degradation 1-like gene dysregulation in bicuspid aortic valve. The Journal of thoracic and cardiovascular surgery 2005;130:1531-36.

[42] Yamagishi C, Hierck BP, Gittenberger-De Groot AC, et al. Functional attenuation of UFD11, a 22q11.2 deletion syndrome candidate gene, leads to cardiac outflow septation defects in chicken embryos. Pediatric Research 2003;53:546-553.

[43] Warnes CA, Williams RG, Bashore TM, et al. ACC/AHA 2008 guidelines for the management of adults with congenital heart disease: a report of the American College of Cardiology/American Heart Association Task Force on Practice Guidelines [Writing Committee to Develop Guidelines on the Management of Adults With Congenital Heart Disease]. J Am Coll Cardiol 2008;52:e1-121.

[44] Novaro GM, Griffin BP. Congenital BAVand rate of ascending aortic dilatation. Am J Cardiol 2004;93:525-6.

[45] Emanuel R, Withers R, O'Brien K, et al. Congenitally bicuspid aortic valves: clinicogenetic study of 41 families. Br Heart J 1978; 40: 1402-7.

[46] Clementi M, Notari L, Borghi A, et al. Familial congenital bicuspid aortic valve: a disorder of uncertain inheritance. Am J Med Genet 1996; 62: 336-8.

[47] P. Mills, G. Leech, M. Davies, et al. The natural history of a non-stenotic bicuspid aortic valve. British Heart Journal 1978;40:951-957.

[48] K. L. Chan, W. A. Stinson, J. P. Veinot. Reliability of transthoracic echocardiography in the assessment of aortic valve morphology: pathological correlation in 178 patients. Canadian Journal of Cardiology 1999;15:48-52.

[49] R. Tanaka, K. Yoshioka, H. Niinuma,et al. Diagnostic value of cardiac CT in the evaluation of bicuspid aortic stenosis: comparison with echocardiography and operative findings. American Journal of Roentgenology 2010;195:895-899.

[50] Samuel C. Siu, Candice K. Silversides.BAVDisease. J Am Coll. Cardiol 2010;55;2789-2800.

[51] Bonow RO, Carabello BA, Kanu C, et al. ACC/AHA 2006 guidelines for the management of patients with valvular heart disease: a report of the American College of Cardiology/American Heart Association Task Force on Practice Guidelines [Writing Committee to Revise the 1998 Guidelines for the Management of Patients With Valvular Heart Disease]. J Am Coll Cardiol 2006;48:e1-148.

[52] S. C. Malaisrie, J. Carr, I. Mikati et al. Cardiac magnetic resonance imaging is more diagnostic than 2-dimensional echocardiography in determining the presence of bicuspid aortic valve. The Journal of Thoracic and Cardiovascular Surgery.

[53] Hiratzka LF, Bakris GL, Beckman JA, et al. 2010 ACCF/AHA/AATS/ACR/ASA/SCA/ SCAI/SIR/STS/SVM Guidelines for the diagnosis and management of patients with thoracic aortic disease. A Report of the American College of Cardiology Foundation/ 
American Heart Association Task Force on Practice Guidelines, American Association for Thoracic Surgery, American College of Radiology,American Stroke Association, Society of Cardiovascular Anesthesiologists, Society for Cardiovascular Angiography and Interventions, Society of Interventional Radiology, Society of Thoracic Surgeons, and Society for Vascular Medicine. J Am Coll Cardiol. 2010 6;55[14]:e27-e129

[54] Karayel F, Ozaslan A, Turan AA, et al. Sudden death in infancy due to bicuspid aortic valve. J Forensic Sci. 2006;51[5]:1147-50.

[55] Lamas CC, Eykyn SJ. Bicuspid aortic valve-A silent danger: analysis of 50 cases of infective endocarditis.Clin Infect Dis 2000; 30: 336-41.

[56] Michelena HI, Desjardins VA, Avierinos JF, et al. Natural history of asymptomatic patients with normally functioning or minimally dysfunctional BAVin the community. Circulation 2008; 117:2776-84.

[57] J. J. Fenoglio Jr, H. A. McAllister, C. M. DeCastro. Congenital BAVafter age 20. Am J Cardiol 1977;39:164-169.

[58] Schaefer BM, Lewin MB, Stout KK, et al. The bicuspid aortic valve: an integrated phenotypic classification of leaflet morphology and aortic root shape. Heart 2008;94:1634-1638.

[59] Hoffman JI. Congenital heart disease: incidence and inheritance. Pediatr Clin North Am 1990;37:25-43.

[60] H. I. Michelena, V. A. Desjardins, J. F. Avierinos et al. Natural history of asymptomatic patients with normally functioning or minimally dysfunctional BAVin the community. Circulation 2008;117:2776-2784.

[61] H. I. Michelina, A. D. Khanna, D. Mahoney et al. Incidence of aortic complications in patients with bicuspid aortic valves.The Journal of the American Medical Association. 2011;306:1104-1112.

[62] Tzemos N, Therrien J, Yip J, et al. Outcomes in adults with bicuspid aortic valves. JAMA 2008;300:1317-25.

[63] Michelena HI, Desjardins VA, Avierinos JF, et al. Natural history of asymptomatic patients with normally functioning or minimally dysfunctional BAVin the community. Circulation 2008;117:2776-84.

[64] Turina J, Turina M, Krayenbühl HP. [Significance of the BAVin the incidence of aortic valve defects in adults]. Schweiz Med Wochenschr. 1986;116[44]:1518-23.

[65] Matsumura T, Ohtaki E, Misu K, et al. Etiology of aortic valve disease and recent changes in Japan: a study of 600 valve replacement cases. Int J Cardiol. 2002;86[2-3]: 217-23. 
[66] Wallby L, Janerot-Sjoberg B, Steffensen T, et al. T lymphocyte infiltration in nonrheumatic aortic stenosis: a comparative descriptive study between tricuspid and bicuspid aortic valves. Heart 2002;88:348-51.

[67] Fenoglio JJ Jr, McAllister HA Jr, DeCastro CM, et al. Congenital BAVafter age 20. Am J Cardiol. 1977;39[2]:164-9.

[68] Roman MJ, Devereux RB, Niles NW, et al. Aortic root dilatation as a cause of isolated, severe aortic regurgitation. Prevalence, clinical and echocardiographic patterns, and relation to left ventricular hypertrophy and function. Ann Intern Med 1987;106:800-7.

[69] Roberts WC, Morrow AG, McIntosh CL,et al. Congenitally BAVcausing severe, pure aortic regurgitation without superimposed infective endocarditis. Analysis of 13 patients requiring aortic valve replacement. Am J Cardiol 1981;47:206-9.

[70] Morishita A, Shimakura T, Nonoyama M, et al. Ascending aorta dissection associated with bicuspid aortic valve. Considerations 4 years after combined coronary artery bypass grafting and mitral valve replacement. Jpn J Thorac Cardiovasc Surg. 2001;49[6]:368-72.

[71] Hahn RT, Roman MJ, Mogtader AH, et al. Association of aortic dilation with regurgitant, stenotic and functionally normal bicuspid aortic valves. J Am Coll Cardiol. 1992;19[2]:283-8.

[72] Collins MJ, Dev V, Strauss BH, Fedak PW, Butany J. Variation in the histopathological features of patients with ascending aortic aneurysms: a study of 111 surgically excised cases. J Clin Pathol. 2008;61[4]:519-23.

[73] Cotrufo M, Della Corte A, De Santo LS, et al. Different patterns of extracellular matrix protein expression in the convexity and the concavity of the dilated aorta with bicuspid aortic valve:preliminary results. J Thorac Cardiovasc Surg. 2005;130:504-11.

[74] Edwards WD, Leaf DS, Edwards JE. Dissecting aortic aneurysm associated with congenital bicuspid aortic valve. Circulation. 1978;57[5]:1022-5.

[75] N. Tzemos, E. Lyseggen, C. Silversides et al. Endothelial function, carotid-femoral sti ' ness, and plasma matrix metalloproteinase-2 in men with BAVand dilated aorta," Journal of the American College of Cardiology 2010;55:660-668.

[76] Ando M, Okita Y, Matsukawa R, et al. Surgery for aortic dissection associated with congenital bicuspid aortic valve. Jpn J Thorac Cardiovasc Surg. 1998;46[11]:1069-73.

[77] Fedak PW, de Sá MP, Verma S, et al. Vascular matrix remodeling in patients with BAVmalformations: implications for aortic dilatation. J Thorac Cardiovasc Surg. 2003;126[3]:797-806.

[78] McKusick VA. Association of congenital BAVand erdheim's cystic medial necrosis. Lancet.1972;1[7758]:1026-7. 
[79] Keane MG, Wiegers SE, Plappert T, Pochettino A, Bavaria JE, Sutton MG. Bicuspid aortic valves are associated with aortic dilatation out of proportion to coexistent valvular lesions.Circulation. 2000;102[19 Suppl 3]:III35-9.

[80] Sá M, Moshkovitz Y, Butany J, David TE. Histologic abnormalities of the ascending aorta and pulmonary trunk in patients with BAVdisease: clinical relevance to the Ross procedure. J Thorac Cardiovasc Surg.1999;118[4]:588-94.

[81] Schmid FX, Bielenberg K, Holmer S, et al. Structural and biomolecular changes in aorta and pulmonary trunk of patients with aortic aneurysm and valve disease: implications for the Ross procedure. Eur J Cardiothorac Surg. 2004;25[5]:748-53.

[82] Nistri S, Sorbo MD, Basso C, Thiene G. Bicuspid aortic valve: abnormal aortic elastic properties. J Heart Valve Dis. 2002 May;11[3]:369-73.

[83] Parai JL, Masters RG, Walley VM, Stinson WA, Veinot JP. Aortic medial changes associated with bicuspid aortic valve: myth or reality? Can J Cardiol 1999; 15:1233-8.

[84] De Backer JF, Devos D, Segers P, Matthys D, Francois K, Gillebert TC et al.Primary impairment of left ventricular function in Marfan syndrome. Int J Cardiol 2006;112:353-8.

[85] Bonderman D, Gharehbaghi-Schnell E, Wollenek G, et al. Mechanisms underlying aortic dilatation in congenital aortic valve malformation. Circulation.1999;99:2138 2143.

[86] Pape LA, Tsai TT, Isselbacher EM, et al., on behalf of International Registry of Acute Aortic Dissection [IRAD] Investigators. Aortic diameter $>5.5 \mathrm{~cm}$ is not a good predictor of type A aortic dissection: observations from the International Registry of Acute Aortic Dissection [IRAD]. Circulation 2007;116:1120-7.

[87] W. M. Gersony, C. J. Hayes, D. J. Driscoll et al., "Bacterial endocarditis in patients with aortic stenosis, pulmonary stenosis, or ventricular septal defect," Circulation, vol. 87, no.2, pp. I121-I126, 1993.

[88] Lamas CC, Eykyn SJ. Bicuspid aortic valve--A silent danger: analysis of 50 cases of infective endocarditis. Clin Infect Dis. 2000;30[2]:336-41.

[89] Nishimura RA, Carabello BA, Faxon DP, et al. ACC/AHA 2008 guideline update on valvular heart disease: focused update on infective endocarditis: a report of the American College of Cardiology/American Heart Association Task Force on Practice Guidelines.J Am Coll Cardiol 2008;52:676-85.

[90] Johnson AD, Detwiler JH, Higgins CB. Left coronary artery anatomy in patients with bicuspid aortic valves. Br Heart J. 1978;40[5]:489-93.

[91] Labombarda F, Legallois D, Sabatier R. Spontaneous coronary artery dissection and bicuspid aortic valve. Arch Cardiovasc Dis. 2009;102[12]:857-8. 
[92] Yokoyama S, Ashida T, SugiyamaT, et al. An autopsied case with a BAVwho had progressive angina pectoris and heart failure during follow-up of 27 years. Nippon Ronen Igakkai Zasshi 2002;39:444-447.

[93] Yuan SM, Jing H, Lavee J.The BAVand its relation to aortic dilation. Clinics [Sao Paulo] 2010;65:497-505.

[94] Shi-Min Yuan, Hua Jing. The BAVand related disorders. Sao Paulo Med J. 2010; 128[5]:296-301.

[95] Chuangsuwanich T, Warnnissorn M, Leksrisakul P, et al. Pathology and etiology of 110 consecutively removed aortic valves. J Med Assoc Thai. 2004;87[8]:921-34.

[96] Pleet AB, Massey EW, Vengrow ME. TIA, stroke, and the bicuspid aortic valve. Neurology.1981;31[12]:1540-2.

[97] Mahajan N, Khetarpal V, Afonso L. Stroke secondary to calcific bicuspid aortic valve: Case report and literature review. J Cardiol. 2009;54[1]:158-61.

[98] Shores J, Berger KR, Murphy EA, et al. Progression of aortic dilatation and the benefit of long-term beta-adrenergic blockade in Marfan's syndrome. N Engl J Med 1994;330:1335-41.

[99] Stewart BF, Siscovick D, Lind BK, et al. Clinical factors associated with calcific aortic valve disease. Cardiovascular Health Study. J Am Coll Cardiol 1997;29:630-4.

[100] H. M. Rosenfeld, M. J. Landzberg, S. B. Perry, et al. Balloon aortic valvuloplasty in the young adult with congenital aortic stenosis. Am J Cardiol 1994;73:1112-1117.

[101] David TE, Omran A, Ivanov J, et al. Dilation of the pulmonary autograft after the Ross procedure. J Thorac Cardiovasc Surg 2000;119:210-20.

[102] Silversides CK, Colman JM, Sermer M, et al.Early and intermediate-term outcomes of pregnancy with congenital aortic stenosis. Am J Cardiol 2003;91:1386-9.

[103] Tzemos N, Silversides CK, Colman JM, et al. Late cardiac outcomes after pregnancy in women with congenital aortic stenosis. Am Heart J 2009;157:474-80.

[104] Lambert EC, Menon VA, Wagner HR, Vlad P. Sudden unexpected death from cardiovascular disease in children. A cooperative international study. Am J Cardiol 1974;34:89-96.

[105] Graham TP Jr, Driscoll DJ, Gersony WM, et al.Task Force 2: congenital heart disease. J Am Coll Cardiol 2005;45:1326-33. 